\title{
Organometallic compound derivates as a novel efficient electron injection layer for hybrid light-emitting diodes
}

\author{
Yasemin TORLAK ${ }^{1^{*}}$ \\ ${ }^{l}$ PamukkaleUniversity, Cal Vocational High School
}

\begin{abstract}
In this study we have presented the use of a organometallic compounds derivates (Keggin type polyoxometalates) for the production of powerful electron injection layer between the emissive polymer layer (PFO) and cathode layer (Al) . Electron transport studies in organometallic compounds layers showed efficient electron transport in very thin structures. High efficiency solution-processed organic light emitting diodes (OLEDs) are achieved by organometallic compounds such as Keggin type polyoxometalates used as electron injection or transport layers with superb electron mobilities and hole blocking capacities. These results indicate the potential for organometallic compounds derivates as a variable, emerging new class of efficient electron injection/transport molecular materials for high performance air-stable HyLEDs. The Keggin type polyoxometalates show unique features such as superior ionization energy and low electron affinity which conversion them as efficient electron injection/hole blocking layers and, immensely high electron mobility.
\end{abstract}

\section{Key Words}

"Polyoxometalate, hybrid light-emitting diode, Keggin." 


\section{INTRODUCTION}

Recently organic light-emitting diodes (OLED) derived from conductive polymers have be a focus of interested as they are marked the most prospect elements for the low cost generation of following lineage flexible screens and solid-state enlightenment references (Komoda et al., 2008).

In turn for organic light-emitting diodes derived from conductive polymers to acquire their complete potential, limit of operating voltage, perfect performance and device stability are called for and important progress to solve these matters has been made in recent years. On the other hand, organic light-emitting diodes arise from conductive polymers efficiency and operating voltage are unfortunately restricted by the fairly large energetic gap among the generally high lying lowest unoccupied molecular orbital level (LUMO) of most conductive polymers and the large work-function of non degradable in air cathode like Al metal electrodes (Brown et al., 2001), alongside some polymers low electron mobility (Laquai et al., 2007). Nowadays, superior electron mobility inorganic metal oxides (Bolink et al., 2007), (Haque et al., 2007) solution-processable conjugated polyelectrolytes (Tokmoldin et al., 2009), (Wang et al., 2006) dielectrics and have been suggested as differents to low work-function metals increase electron injection, lower the operating voltage and device balance.

Organometallic compound derivates especially, transition metal oxides with a energy states close to the ground-state level like $\mathrm{ZnO}(4.2 \mathrm{eV})$ and $\mathrm{TiO}_{2}(3.8 \mathrm{eV})$ (Wang et al., 2006) also dielectric oxides like $\mathrm{ZrO}_{2}(3.0 \mathrm{eV})$ (Jin et al., 2008) have been utilized as electron injection (EIL)/transport (ETL) layers as they decrease the injection obstacle at the cathode between polymer interface. In a study by Glezos et al. has indicate that a agency of the category of polyoxometalates (POMs) (Pope et al., 1991), a member of water soluble inorganic molecular transition oxides whose various chemistry admits for facile regulation of their structural, optical and electronic properties, shows a excellent electron mobility (Glezos et al., 2003) and has a low lying conduction-band edge deposited at $4.0 \mathrm{eV}$. Moreover, electron transport works in polyoxometalate layers exhibited excellent electron transport in very thin structures (Douvas et al., 2008). These properties make it a very appealing candidate for use as an elecron injection layer hybrid light-emitting diodes.

In this study we reported for the use of a two different derivates of water-soluble POMs (B1-W and B1-Mo) exhibiting the lacunary Keggin structure polyoxometalates $\left.\left(\mathrm{PW}_{12} \mathrm{O}_{40}\right)^{3-}\right)$ (Glezos et al., 2003) as a novel electron injection layer in HyLEDs. In particular, green fluorescent OLEDs using PFO as the emissive layer and B1-Mo as the electron transport material gave $19.5 \mathrm{~lm}$ $\mathrm{W}^{-1}$ and $40.0 \mathrm{~cd} \mathrm{~A}^{-1}$ capacity and luminous efficiency, respectively. POM derivates as a novel efficient electron injection layer with a LUMO level lying between that of the emissive polymer layer and the Fermi level of Al, ensures an medium step for easing and enhancement electron injection between $\mathrm{Al}$ and the polymer LUMO, as incorporated between the light-emitting layer and Al. All this conclusions in a decreased turn-on voltage and a important reduce of the operating voltage also a high increase increase in the high current density, normalized intensity and luminance, enhancing the total efficiency of the hybrid lightemitting diodes.

\section{EXPERIMENTAL SECTION}

Synthesis of organometallic compounds derivates (POMs). $\mathrm{Na}_{2} \mathrm{WO}_{4} \cdot 2 \mathrm{H}_{2} \mathrm{O}(181.5 \mathrm{~g}, 0.550 \mathrm{~mol})$ dissolved in $300 \mathrm{~mL}$ water and were incorporated $50 \mathrm{~mL}$ of $\mathrm{H}_{3} \mathrm{PO}_{4} 1 \mathrm{M}$ and $88 \mathrm{~mL}$ of glacial $\mathrm{CH}_{3} \mathrm{COOH}$. The solution was stirred throughout one hour. $\mathrm{Next}, \mathrm{KCl}(60 \mathrm{~g}, 0.805 \mathrm{~mol})$ were added to solution also the white precipitate washed with cooled deionized water and dried in at room temperature to obtain the B-1-W (Contant, 1987).

Devices preparation. The devices are processed according to the sequence of coatings shown so that the measurement is ready. These process are as follows;

a-) Surface abrasion and $\mathrm{Uv}$ ozone treatment (The conductive layer of part of our $\mathrm{HNO}_{3}-\mathrm{HCl}-\mathrm{Si}$ devices is removed to avoid short circuit.) For the anode ITO coated on glass is used. ITO electrodes are cut in $1.5 \mathrm{~cm}$ x $1.5 \mathrm{~cm}$ in the construction of the OLED device and a 0.3-0.5 cm edge is removed by chemical etching. Prepared bases are cleaned with acetone, isopropyl alcohol and distilled water respectively for 15 minutes in ultrasonic bath and dried with nitrogen gun. Uv ozone treatment (Cleaning effect is generated by scattering these rays on the surface with appropriate bulbs which can generate enough energy in the ultraviolet spectrum.) This reactive ozone is the process of removing organic impurities from the oxygen separated from the atoms. Thus, the volatile hydrocarbons released from the surface are expelled. Oxygen plasma at 60 watt and 5cc is applied for 2 minutes to increase the (oxygen) $\mu$-oxo group, which removes nano-sized dirt on the surface of the cleaned glass and allows the organic molecules to adhere better to the surface. By separating the hydrocarbons from the surface, ultra clean ITO coated surfaces with high wettability are obtained and ready for use.

b-) Coating of thin films. The glass surfaces are cleaned with pressurized nitrogen before the ITO glasses with increased hydrophilic properties by Uv-ozone are introduced into the coating process and immediately placed in the spin coating device. Poly (3,4-ethylenedioxythiophene) poly (styrenesulfonate) (PEDOT: PSS) with high conductivity is used as the void transfer material so that the glass surface is completely covered. After filtering to $0.45 \mu \mathrm{m}$, it is coated on ITO by spin coating method at $4000 \mathrm{rpm}$ for 40 seconds. The coated glass is placed on a clean glass surface and cleaned by wiping the PEDOT: PSS layer with water by $3 \mathrm{~mm}$. The reason for cleaning the PEDOT:PSS layer about $3 \mathrm{~mm}$ is that the bottom electrode will come to this area and 
this area will be covered with Al. After the PEDOT:PSS (40 $\mathrm{nm})$ coating and cleaning process is finished, the glasses are dried under vacuum at $120^{\circ} \mathrm{C}$.

c-) Coating of light-emitting layer (PFO). $10 \mathrm{mg} / \mathrm{ml}$ solutions of organic materials were used. Since the prepared OLED device contains different layers, some layers require spin coating and some require vacuum evaporation. The light is coated at $1000 \mathrm{rpm}$ with cyclic coating $(100 \mathrm{~nm})$ as the light-emitting layer (PFO). Organic solvent-soluble materials such as PFO can be coated with a spin coating on the PEDOT: PSS layer, but when the coated layer must not be covered with another material soluble in the same class solvent, the vacuum evaporation system is preferred at this stage.

d) Coating of POM, which is an electron acceptor, that is $\mathrm{n}$ type semiconductors. $10 \mathrm{mg} / \mathrm{mL}$ solutions of POM material were used. Coated with cyclic coating at $4000 \mathrm{rpm}$ for 40 seconds. In order to make the anode contact, these layers were wiped with a cotton ball with their own solvents (water, methanol, acetonitrile) after each coating. After the cleaning process is finished, the glasses are dried under vacuum at $120^{\circ} \mathrm{C}$.

e) Finally, the cathode $(\mathrm{Al})$ contacts are covered with a thermal metal evaporation system (PVD) in a nitrogen atmosphere in a thickness of $100 \mathrm{~nm}$.

\section{Characterization methods.}

Structural analyzes of the synthesized compounds were investigated by ${ }^{31} \mathrm{P}-\mathrm{NMR},{ }^{1} \mathrm{H}-\mathrm{NMR}$, TGA and FT-IR, optical properties UV, electrochemical properties of alternating voltammetry and surface properties by SEM and AFM techniques. The characterization of the structures of the synthesized polyoxometallates was confirmed by FT-IR (Bruker Vertex 70), UV-vis (Hitachi-U4100), SEM (ZeissEvo LS10), AFM (NT- MDT, Ntegra Solaris), 31P- 400, CH instruments (660B Electrochemical workstation) were used.

The Ocean Optics USB 2000 fiber optic spectrophotometer was used to characterize the luminances and electroluminescence spectra and the Lambertian emission profile was used to evaluate the luminance. The current density-voltage characteristics were gauged with a Keithley 2400 source measurement unit.The Veeco atomic force microscope (AFM) was used to study the surface morphology of POM and PFO layers coated on ITO, and all measurements were performed at room temperature in general.

\section{RESULTS AND DISCUSSION}

The vibrational frequencies observed for the $\left[\mathrm{PW}_{11} \mathrm{O}_{39}\right]^{7-}$ anions in tetrabutylammonium $\left(\mathrm{Bu}_{4} \mathrm{~N}\right)^{+}$salts are very close to those of the anions due to the electronic properties of the anions. Monolacunary $\alpha-\mathrm{K}_{7-\mathrm{x}} \mathrm{Na}_{\mathrm{x}}\left[\mathrm{PW}_{11} \mathrm{O}_{39}\right] \cdot 14 \mathrm{H}_{2} \mathrm{O}$ (B-1) and trilacunary $\alpha-\mathrm{K}_{9}\left[\mathrm{PW}_{9} \mathrm{O}_{34}\right] \cdot 16 \mathrm{H}_{2} \mathrm{O}$ (B-2) Keggin type Polyoxometalates, are prepared according to the method of Contant (Contant, 1987).

Infrared spectroscopy analysis shows some frequencies for the $\mathrm{P}_{-} \mathrm{O}_{\mathrm{i}}$ stretch observed at the $\mathrm{PO}_{4}$ tetrahedron center, which is consistent with literature data at 1086 and $1043 \mathrm{~cm}^{-1}$ for B-1 and 1054 and $1003 \mathrm{~cm}^{-1}$ for B-2 (as seen in Figure 1). The B-2 compound is formed by the alkalisation of the control of the B-1 compound formed by the acidification of the WO $4^{2-}$ oxo anion in the aqueous solution.

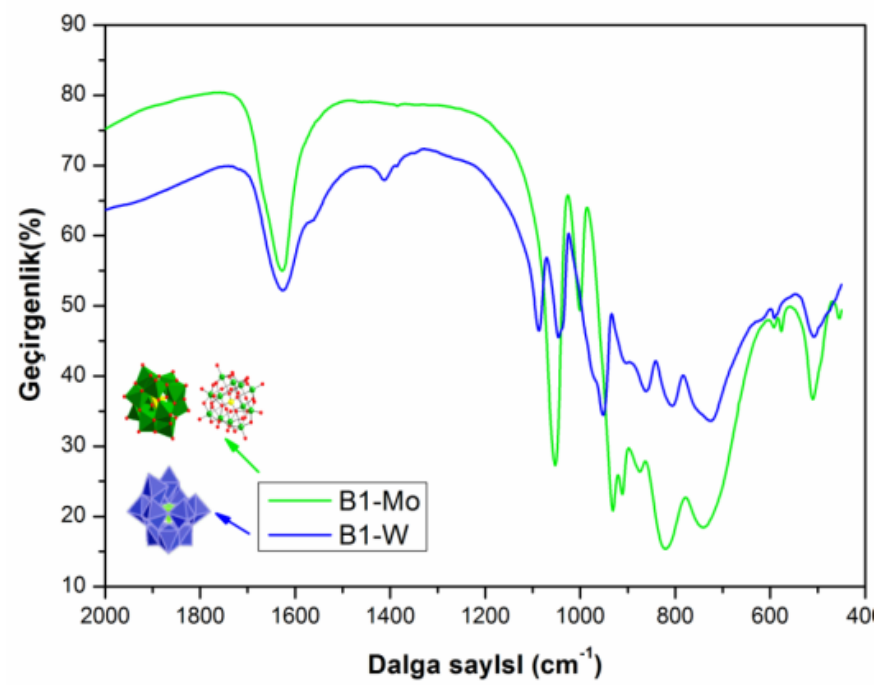


Figure 1. Comparison of FT-IR spectra of $\alpha-\mathrm{K}_{7-\mathrm{x}} \mathrm{Na}_{\mathrm{x}} \mathrm{PW}_{11} \mathrm{O}_{39} \cdot 14 \mathrm{H}_{2} \mathrm{O}$ (B-1) and $\alpha-\mathrm{K}_{7-\mathrm{x}} \mathrm{Na}_{\mathrm{x}} \mathrm{PMo}_{11} \mathrm{O}_{39} \cdot 14 \mathrm{H}_{2} \mathrm{O}(\mathrm{B} 1-\mathrm{Mo})$ compounds.

The ${ }^{1} \mathrm{H}-\mathrm{NMR}$ and ${ }^{31} \mathrm{P}-\mathrm{NMR}$ results of the synthesized Keggin structure of POMs and their W, Mo derivatives are given below. Chemical shift values are given above the spectra.

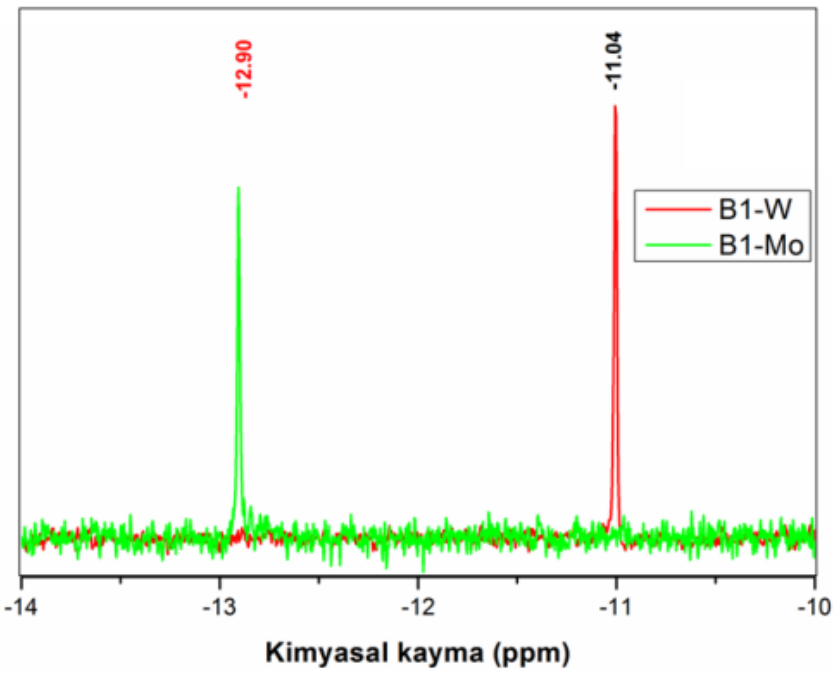

Figure 2. Comparison of ${ }^{31} \mathrm{P}$ NMR (121.49 MHz, $\left.\mathrm{D}_{2} \mathrm{O}\right)$ spectra of $\mathrm{B} 1$ and $\mathrm{B} 1-\mathrm{Mo}$ compounds in $\mathrm{DH}_{2} \mathrm{O}-\mathrm{d} 6$ at room temperature

When an external magnetic field is applied, a magnetic field is formed in the opposite direction of the external magnetic field in the electron cloud surrounding the core. As electrons are affected from this area, the ${ }^{31} \mathrm{P}$ nuclei with different chemical entrances enter the resonance in the negative magnetic field and the spectra of the POM compounds appear in the negative region. OLED devices structure including used to polyfluorene copolymer used in the emissive layer, B1-W and B1-Mo polyoxometalates used in the electron transport layer respectively, in the Figure 1a is shown.

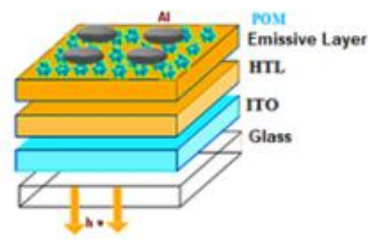

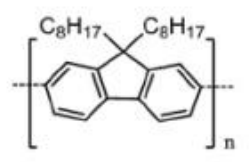

PFO

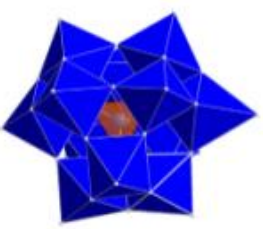

POM

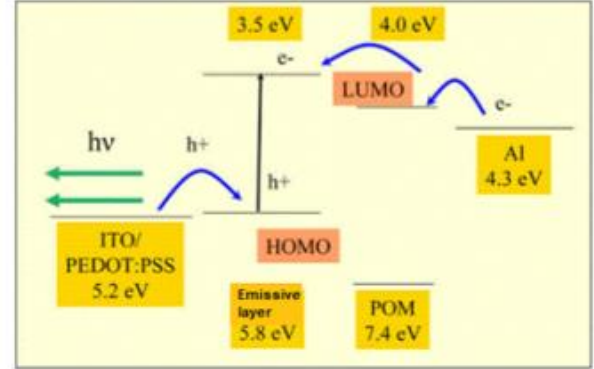

b)

a)

b) Energy diagram

The fluorescent OLEDs were fabricated via spin coating to serve as PFO as the emissive layer, POM to operate as the electron injection/transport layers. Finally, the cathode $(\mathrm{Al})$ contacts are coated in a nitrogen atmosphere with a thermal metal evaporation system (PVD) to be $100 \mathrm{~nm}$ thick. The schematic illustration in Figure 4. shows a sample OLED device preparation scheme used in our studies. 


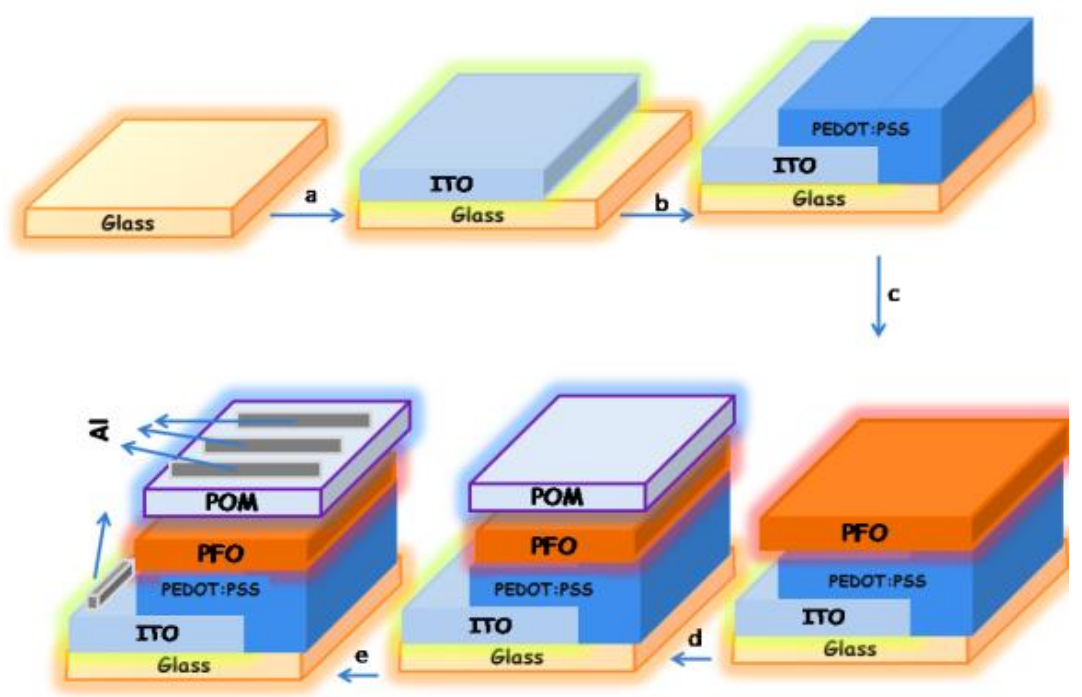

Figure 4. Scheme for the preparation of OLED device.

The results obtained in the studies conducted are examined below Figure 5. also shows the electroluminescence graph against the current values of the OLED.

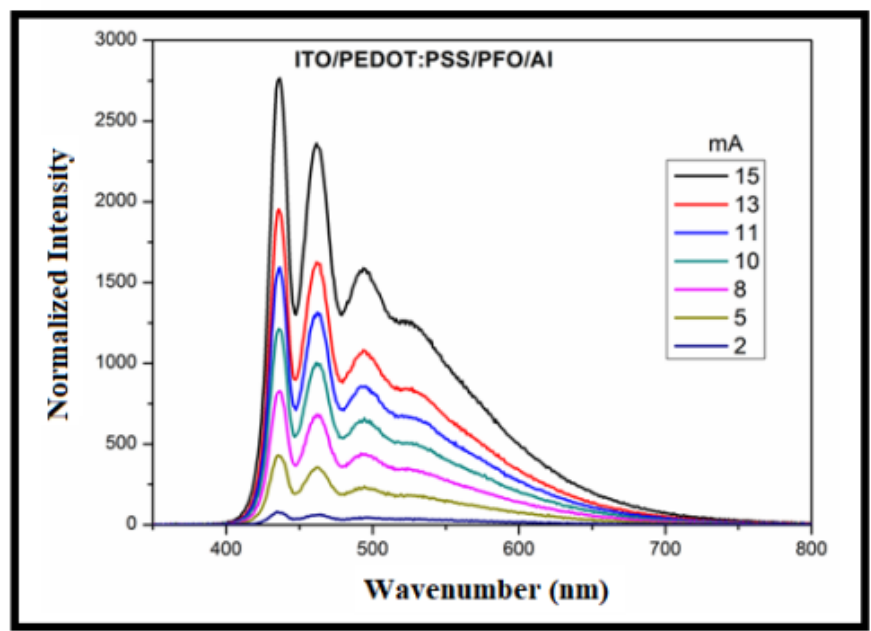

Figure 5. Electroluminescence graph of OLED devices with PFO based not doped with POM at different current intensities

As can be seen in Figure 5, a steady increase in electroluminescence has been observed in measurements made at a current density of $15 \mathrm{~mA}$ comparative graph of the reference OLED structure without POM for the same current value. 


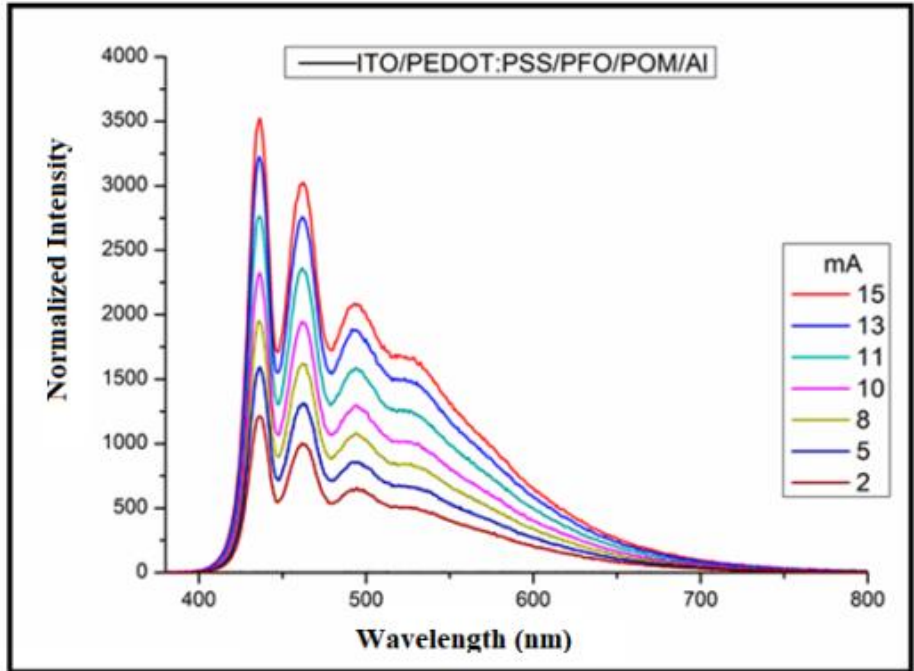

Figure 6. Electroluminescence graph of PFO based OLEDs doped with POM at different current intensities

Figure 5. and Figure 6. shows comparative radiation intensity-current density plots of POM-doped and undoped OLEDs coated with spin at $4000 \mathrm{rpm}$. When POM-doped OLED and non-doped OLED were compared, the highest light intensity observed at 2,700 cd/ $\mathrm{m}^{2}$ in the undoped OLED structure reached a value of around $3,500 \mathrm{~cd} / \mathrm{m}^{2}$ by the addition of POM. This corresponds to an increase of nearly $23 \%$.

The variation on the surface topography and include between the POM film on ITO and the POM to the PFO polymer film also the inhomogeneities offer in both cases as can be seen from the comparison of Figure 7. Polar hydrophilic molecules on the surface of this difference can be due to different wetting rates. To evaluate the AFM topographic images, although the POM layer is homogeneously coated on the PFO layer, the increased leakage current flow and the nanostructures between aluminum and POM increase the interface - is anticipated to be advantages for charge injection because of the high local electric field existing in the surroundings of POM fields.
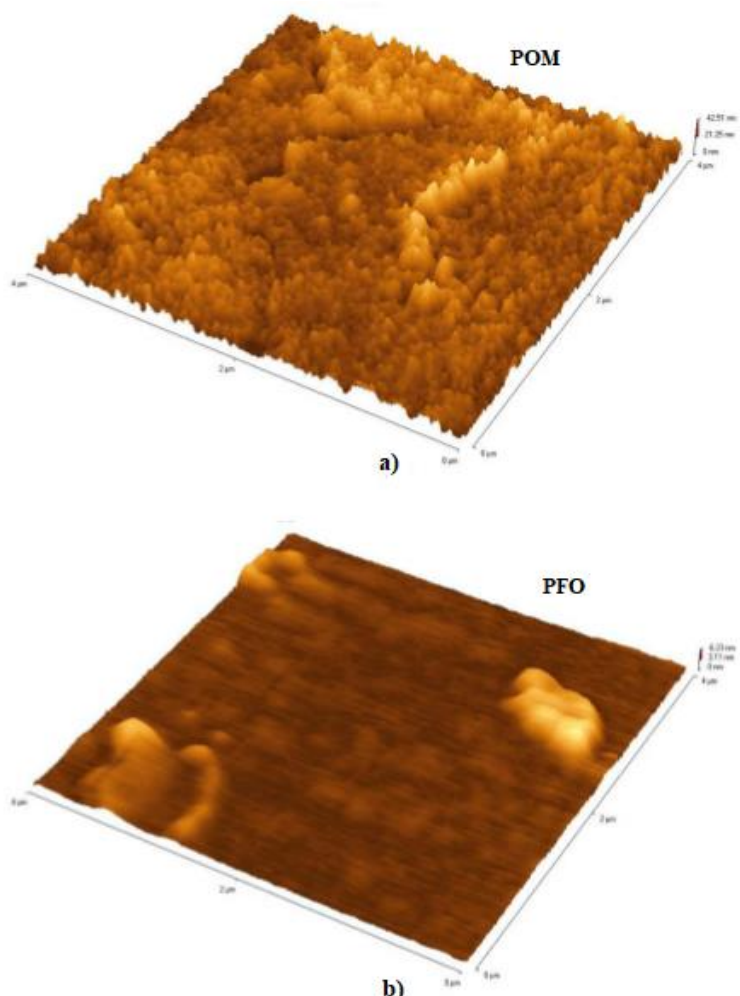

b)

Figure 7. 3D AFM topographic images of (a) POM coated indium tin oxide (b) emissive layer (PFO) film 
A wide interfacial contact area with rised surface roughness was sighted as POM was added at the PFO/Al interface. When this result is evaluated that technique was used to interpret electron mobilities of POM including films and the thicknesses of POM films, the resulting values are usually highly equal and very high. These high efficiency values are coherent with efficient device process in both fluorescent and phosphorescent OLEDs as confirmed from our input.

\section{CONCLUSIONS}

In summary, we have showed the use of a the Keggin structure lacunary polyoxometalates soluble in water, the B1-W and B1Mo for the formation of a novel thin, exhibit the advantages of the superior electron injection and electron mobility characteristics high ionization energy and low electron affinity for use as electron transport materials in OLED devices. These results show that fine designing of an electron transport materials with a view to join different attractive properties is an powerful aspect to further increase performance of next generation the next generation of display technologies.

\section{ACKNOWLEDGMENT}

This study was supported by Pamukkale University Institute of Natural and Applied Sciences as BAP project (2017KKP131).

\section{REFERENCES}

A.M. Douvas, E. Makarona, N. Glezos, P. Argitis, J.A. Mielczarski, E. Mielczarski, "Polyoxometalate-based layered structures for charge transport control in molecular devices", ACS Nano 2, 733, 2008.

T. Komoda, N. Ide, J. Kido, J.,’High Efficient OLEDs and Their Application to Lighting”, Light Vis. Environ. $32,75 ., 2008$.

T.M. Brown, R.H. Friend, I.S. Millard, D.J. Lacey, J.H. Burroughes, F. Cacialli, "Efficient electron injection in blue-emitting polymer light-emitting diodes with LiF/Ca/Al cathodes”, Appl. Phys. Lett. 79,174, 2001.

F. Laquai, G. Wegner, H. Bässler, Phil., “What determines the mobility of charge carriers in conjugated polymers?”,Trans. R. Soc. A 365,1473, 2007.

H.J. Bolink, E. Coronado, D. Repetto, M. Sessolo, Hybrid organic-inorganic light emitting diodes: effect of the metal oxide, Appl. Phys. Lett. 91,223501, 2007. 223501.

S.A. Haque, S. Koops, N. Tokmoldin, J.R. Durrant, J.S. Huang, D.D.C. Bradley, E. Palomares, “A Multilayered Polymer LightEmitting Diode Using a Nanocrystalline Metal-Oxide Film as a Charge-Injection Electrode”, Adv. Mater. 19, 683, 2007.

N. Tokmoldin, N. Griffiths, D.D.C. Bradley, S.A. Haque, “A Hybrid Inorganic-Organic Semiconductor Light-Emitting Diode Using $\mathrm{ZrO}_{2}$ as an Electron-Injection Layer”, Adv. Mater. 21,1, 2009.

L. Wang, B. Liang, F. Huang, J. Peng, Y. Cao, "Utilization of water/alcohol-soluble polyelectrolyte as an electron injection layer for fabrication of high-efficiency multilayer saturated red-phosphorescence polymer light-emitting diodes by solution processing", Appl. Phys. Lett. 89, 151115, 2006.

Y. Jin, G.C. Bazan, A.J. Heeger, J.Y. Kim, K. Lee, "Improved electron injection in polymer light-emitting diodes using anionic conjugated polyelectrolyte”, Appl. Phys. Lett. 93, 123304, 2008.

N. Glezos, P. Argitis, D. Velessiotis, C.D. Diakoumakos, “Tunneling transport in polyoxometalate based composite Materials", Appl. Phys. Lett., 83, 488 ,2003.

M.T. Pope, A. Muller, "Polyoxometalates: From Platonic Solids To Anti-Retroviral Activity”, Angew. Chem., Int. Ed. Engl. 30,34, 1991.

R. Contant, "Relation entre les tungstophophates apparentés à l'anion $\mathrm{PW}_{12} \mathrm{O}_{40}{ }^{3-}$. Synthèse et propriétés d'un nouveau polyoxotungstophosphate lacunaire $\mathrm{K}_{10} \mathrm{P}_{2} \mathrm{~W}_{20} \mathrm{O}_{70} \cdot 24 \mathrm{H}_{2} 0$ ”, Can. J. Chem., 65, 568-573., 1987. 